\title{
REVITALISASI LEGENDA BATU HODA MELALUI NASKAH DRAMA
}

\author{
Donganta $^{1}$, Febri Yanti Arfansyah Harapan ${ }^{2}$, Sartika Sari $^{3}$ \\ Universitas Prima Indonesia ${ }^{1}$, Universitas Prima Indonesia ${ }^{2}$, Universitas Prima Indonesia 3 \\ Pos-el: dongantah@gmail.com ${ }^{1}$, febriyanti.17hrp@gmail.com ${ }^{2}, \underline{\text { sartikasari@ unprimdn.ac.id }} 3$
}

\begin{abstract}
The legend of Batu Hoda is a folk tale from the Simanindo sub-district, Samosir district, which tells of a mare who is waiting for her lover a stallion to meet on the shores of Lake Toba. The form of the story about the origin of Batu Hoda is not yet known by many people, this is due to the lack of innovation in telling stories to the community, especially children. Therefore, people have lost interest in telling or curiosity about legends. The research method used is a qualitative approach with the aim of finding information about the story of Batu Hoda. As the main design, such as interviews with several informants or the surrounding community. The results of this study were formulated in the form of researching the legend of Batu Hoda in the form of presenting the story that was played. The selection of drama script media as media is expected to be one of the efforts to preserve folklore. The drama script provides a retelling style with dasi and illustrations and makes it easier for people to get carried away in the Batu Hoda story.
\end{abstract}

Keywords: Simanindo's glasses, Folklore, Drama Script, Batu Hoda

\begin{abstract}
ABSTRAK
Legenda Batu Hoda adalah cerita rakyat dari kecamatan simanindo kabupaten samosir yang menceritakan seekor kuda betina yang sedang menunggu kekasihnya kuda jantan untuk bertemu di tepi Danau Toba. Bentuk cerita tentang asal mula Batu Hoda inii belum diketahui oleh banyak masyarakat, hal ini dikarenakan kurangnya inovasi penyampayan cerita kepada masyarakat khususnya anak-anak. Maka dari itu masyarakat telah kehilangan minat untuk memberitahu ataupun keingintahuan salah satunya mengenai legenda. Metode penelitian yang digunakan ialah pendekatan kualitatif dengan tujuan untuk mencari informasi tentanh cerita Batu Hoda. Sebagai perancangan utama, seperti wawancara kepada beberapa informan atau masyarakat sekitar. Hasil penelitian ini dirumuskan dalam bentuk pencaritaan ulang legenda Batu Hoda dalam bentuk penyajian cerita yang diperankan. Pemilihan media naskah drama sebagai media diharapkan dapat menjadi salah salah satu usaha pelestarian cerita rakyat. Naskah drama memberikan gaya penceritaan ulang dengan darasi dan ilustrasi serta memudahkan masyarakat terbawa dalam cerita Batu Hoda.
\end{abstract}

Kata Kunci: Kacamatan Simanindo, Cerita Rakyat, Naskah Drama, Batu Hoda 


\section{PENDAHULUAN}

Indonesia merupakan negara yang kaya akan cerita rakyatnya, salah satunya legenda yang tersebar di beberapa pulau yang ada di Indonesia, tidak terkecuali di Sumatera utara, tepatnya di Kecamatan Simanindo di Dusun Malau, terdapat Legenda dari masyarakat Batak Toba yaitu Legenda Batu Hoda. Secara umum Legenda Batu Hoda ini masih sering di ceritakan melalui lisan kelisan oleh masyarakat yang ada di sekitar.

Menurut Danandjaja, (1998:66) Legenda seringkali dipandang sebagai "sejarah" kolektif (folk history) walaupun sejarah itu tidak tertulis telah mengalami distorsi, sehingga seringkali dapat jauh berbeda dengan kisah aslinya. Oleh karenanya, apabila hendak menggunakan legenda sebagai bahan untuk penyususnan sejarah suatu folk, kita harus membersihkan dahulu bagian-bagiannya yang memiliki sifat-sifat foklor, misalnya bersifat pralogis atau yang merupakan rumus-rumus tradisi lisan seperti yang dikemukakan oleh Lord Regland (1963:150)". Legenda memiliki kandungan nilai- nilai luhur yang bermanfaat bagi kehidupan masyarakat. Mengingat begitu besar makna legenda bagi masyarakat pendukungnya, maka perlu diadakan suatu kajian mengenai legenda-legenda yang masih dikenal dan hidup pada masyarakat tertentu.

Batu Hoda merupakan titik terjauh pulau Samosir atau titik nol pulau Samosir. Batu Hoda diapit oleh empat Kabupaten yang ada di Sumatera Utara yakni Kabupaten Simalungun, Kabupaten Tanah Karo, Kabupaten Dairi, dan Kabupaten Samosir. Menurut ilmu Sains Batu Hoda termasuk salah satu batu Geosaince dari kaldera toba. Secara geologi dari geodiversity disebut slamping stone. Slamping stone ini di prediksi oleh para geolog sekitar 35000 tahun berada di dasar danau toba di kedalaman 500m dibawah permukaan laut.

Brunvand dalam danandjaja (2002:67) mengemukakan bahwa legenda dapat digolongkan dalam beberapa jenis yaitu legenda keagamaan, legenda perseorangan, legenda alam dan legenda setempat. Dan peneliti memilih salah satu yaitu: legenda setempat, dimana menceritakan tentang terjadinya susunan batu, dan makna yang terkandung dalam cerita tersebut. 
Pada masa ini, budaya memperkenalkan legenda sudah mulai berkurang bahkan hampir hilang, terlebih kepada anak-anak. Hal ini menyebabnya hilangnya rasa cinta terhadap ilmu budaya, salah satu penyebab terjadinya ialah kemajuan teknologi yang semakin canggih sehingga menghilangkan rasa ketertarikan masyarakat pada legenda legenda yang ada di Indonesia khususnya di Sumatera Utara. Selain itu juga dikarenakan minimnya kesadaran orang tua untuk memperkenalkan Legenda local kepada anaknya.

Pada nyatanya cerita tentang asal mula terbentuknya Batu Hoda ini pun belum banyak di ketahui oleh masyarakat luas. Sehingga peneliti melihat hal yang sangat di sayangkan. Hal ini memberi inisiatif untuk peneliti melakukan penelitian terhadap Revitalisasi Batu Hoda Melalui Naskah Drama. Melalui naskah drama masyarakat kususnya anak anak dapat menumbuhkan kembali rasa cinta kepada budaya. Selain itu melalui naskah drama juga dapat memperkenalkan legenda Batu Hoda ini kepada kalangan siswa melalui pembelajaran drama yang ada di sekolah baik dalam ekstrakulikuler maupun dalam pelajaran Bahasa Indonesia. Oleh karena itu peneliti mengangkat judul penelitian Revitalisasi Legenda Batu Hoda Melalui Naskah Drama.

Berdasarkan Latar Belakang Masalah yang diuraikan tersebut, maka yang menjadi identifikasi penelitian ini adalah

1. kemajuan teknologi yang semakin canggih sehingga menghilangkan rasa ketertarikan masyarakat pada legenda legenda yang ada di Indonesia khususnya di Sumatera Utara.

2. Minimnya kebiasaan mayarakat dalam memperkenalkan lagenda kepada anaknya.

Berdasarkan identifikasi masalah tersebut maka peneliti membatasi pokok permasalahan pada "Revitalisasi Legenda Batu Hoda Melalui Naskah Naskah Drama"

Berdasarkan identifikasi masalah di atas maka peneliti merumuskan masalah antara lain:

1. Bagaimana legenda Batu Hoda?

2. Bagaimana revitalisasi legenda Batu Hoda melalui naskah drama?

Adapun tujuan Penelitian ini adalah sebagai berikut:

3. Untuk mengetahui legenda Batu Hoda 
4. Untuk mengetahui hasil revitalisasi legenda Batu Hoda melalui naskah drama

Adapun manfaat dari penelitian yang akan dilakukan ialah untuk menumbuhkan keinginan masyarakat khususnya anak-anak dalam melestarikan cerita rakyat dan meningkatkan cerita legenda Batu Hoda ini dengan menggunakan media naskah drama yang dapat di gunakan baik dalam pertunjukan sekolah, ataupun luar sekolah.

\section{Metode Penelitian}

Lokasi penelitian berada di Dusun Malau, Desa Cinta Dame, Kecamatan Simanindo, Kabupaten Samosir Sumatera Utara. Waktu penelitian dilakukan pada tanggal 22 November 2021.

Metode yang digunakan pada Revitalisasi Legenda batu Hoda ini ialah Metode Kualitatif. Menurut Sugiyono (2009:15), metode penelitian kualitatif merupakan penelitian yang digunakan untuk menelaah, menemukan, mendeskripsikan, serta menjelaskan kualitas atau keistimewaan dari hasil social yang tidak dapat dijelaskan, diukur atau digamberkan melalui pendekatan kualitatif. Maka dari itu peneliti harus memiliki bekal teori dan wawasan yang cukup luas agar dapat melakukan wawancara eksklusif terhadap informan.

Data dalam penelitian ini merupakan teks verbal dan tertulis dari naskah, cerita, informasi, maupun transkrip teks dari informan mengenai cerita Legenda Batu Hoda sumber data pada penelitian ini, yaitu (1) informan; dan (dua) dokumentasi tertulis. Informan dalam penelitian ini yaitu tokoh rakyat, rakyat yang bermukim di Kabupaten Samosir, memiliki pengetahuan lengkap perihal keberadaan serta cerita perihal Legenda Batu Hoda. Dokumentasi tertulis yang dimaksud yaitu berupa situs internet yg berafiliasi dengan eksistensi dan cerita Legenda Danau Batu Hoda.

Teknik pengumpulan data dalam penelitian ini meliputi wawancara, dan studi kepustakaan. Instrumen pengumpulan data yang digunakan untuk mengumpulkan data dalam penelitian ini berupa wawancara, dan panduan pemilihan dokumentasi. Data yang terkumpul akan terjamin kevaliditasnya jika peneliti sendiri yang terjun ke lapangan. Oleh karena itu, penelitian ini melibatkan peneliti secara langsung di lapangan.

Prosedur penelitian merupakan bagian yg krusial di dalam suatu penelitian. 
Adapun langkah-langkah mekanisme penelitian yaitu:

\section{a. Tahap Perencanaan}

Pada tahap ini peneliti masih sampai pada aktivitas menyusun perumusan masalah, penyusunan rancangan penelitian dan memilih bagaimana cara pada pengumpulan data. sesuai dengan uraian sebelumnya, di penelitian ini ada rumusan masalah yaitu: (a) Bagaimana legenda Batu Hoda? (b) Bagaimana revitalisasi legenda Batu Hoda dalam bentuk Naskah Drama?

\section{b. Tahap Pelaksanaan}

Pada tahap ini mencakup pengumpulan data, analisis data dan penarikan kesimpulan. pada tahap pengumpulan data, peneliti memakai dua tahap yakni mengumpulkan data berasal informan guna untuk memperoleh bagaimana legenda Batu Hoda dan tahap analisis data berasal hasil wawancara. di tahap terakhir yaitu penarikan konklusi berupa jawaban dari rumusan masalah.

\section{c. Tahap Pengumpulan Laporan}

Pada tahap ini setelah seluruh data yang dibutuhkan telah terkumpul, dianalisis dan telah disimpulkan. tahap ini yaitu termin memindahkan hasil penelitian yang telah diperoleh kedalam bentuk laporan yang sifatnya ilmiah.

\section{d. Tahap Pengumpulan Laporan}

Pada tahap ini setelah seluruh data yang dibutuhkan telah terkumpul, dianalisis dan telah disimpulkan. tahap ini yaitu termin memindahkan hasil penelitian yang telah diperoleh kedalam bentuk laporan yang sifatnya ilmiah

\section{Hasil Dan Pembahasan}

Hasil penelitian ini memuat tentang cerita yang meliputi asal-usul Legenda Batu Hoda dengan hasil paparan data melalui transkrip yang kemudian di ubah dalam bentuk Naskah Drama. (a) untuk mengetahui legenda Batu Hoda

, (b) untuk mengetahui legenda Batu Hoda dalam bentuk naskah drama. 


\section{Hasil Revitalisasi Legenda Batu Hoda}

Hasil penelitian ini memuat tentang cerita yang meliputi asal-usul cerita Legenda Batu Hoda dengan hasil paparan data melalui transkrip yang kemudian di ubah dalam bentuknaskah drama. (a) untuk mengetahui cerita legenda Batu Hoda (b) untuk mengetahui cerita legenda Batu Hoda dalam bentuk naskah drama. Media yang digunakan adalah naskah drama, dimana naskah drama tersebut menceritakan tentang asal mula dari Legenda Batu Hoda tersebut. Alasan peneliti memilih naskah drama karena naskah drama dapat di gunakan sebagai bahan pembelajaran disekolah baik dalam ekstrakulikuler maupun dalam pelajaran intrakulikuler.

Secara tidak langsung naskah drama yang menceritakan tentang Legenda Batu Hoda ini mengenakan sasaran selain masyarakat umum peneliti juga berfokus pada pelajar.

Berikut cerita legenda legenda Batu Hoda yang akan diceritakan dalam naskah drama:

Pada zaman dahulu di sebuah desa yang terletak di Kabupaten Samosir terdapat desa yang Bernama cinta dame. Di desa tersebut hiduplah masyarakat yang saling bantu membantu satu sama lain, bahkan masyarakat yang hidup di desa tersebut sangat penyayang antar makhluk hidup.

Pada suatu ketika datanglah seekor kuda betina yang menyebrangi danau toba dan berlabu di tepi danau di desa cinta dame. Kuda betina tersebut berdiri tegak dari awal sampai di tepi danau dan tidak beranjak sedikitpun.

Masyarakat yang memperhatikan bertanya tanya apa yang sebenarnya sedang dilakukan oleh kuda betina itu, “apa yang sedang kau tunggu?", tanya seorang masyarakat kepada kuda betina itu dengan rasa penuh penasaran.

"aku sedang menunggu kekasihku" jawab singkat kuda betina itu sembari terus melihat danau toba dengan mata penuh harap sesuatu akan terlihat dari tepi danau. Masyarakat itupun melemparkan pandangannya kedanau mencari yang di maksud oleh kuda betina itu.

"apa kau yakin ia akan menemuimu, lebih baik kau pulang saja sudah tiga hari kau berdiri tegak di tepi danau ini tapi kekasihmu tak kunjung menghampirimu" bujuk salah seorang masyarakat yang merasa kasihan meluhat kuda betina itu berdiri terus menerus.

Mendengar ucapan masyarakat itu kuda betina dengan tegas menolak permintaan 
masyarakat itu, hingga pada akhirnya masyarakat kembali meninggalkan kuda betina itu sendiri lagi.

Hari demi hari, bulan demi bulan berlalu, kuda jantan yang di nanti kuda betina tak kunjung datang hingga pada akhirnya kuda betina itu secara perlahan berubah menjadi batu dan abadi di tempat ia berdiri menanti kekasihnya datang memenuhi janji untuk bertemu di tepi danau toba.

\section{Hasil Revitalisasi Legenda Batu Hoda melalui naskah Drama: \\ Batu Hoda}

\section{Prolog}

Alkisah, Pada zaman dahulu tepatnya di desa hoda, pulau Samosir. hiduplah sepasang kekasih yang telah mengikat janji untuk bertemu di ujung pulau. Rupa mereka saat itu sudah berwujud menjadi kuda. akibat kutukan dari hubungan mereka.

Kuda Jantan : Menyebranglah terlebih dahulu

Kuda Betina : Bagaimana dengammu?

Kuda Jantan : aku akan menyusulmu nanti, tunggu aku di tepi danau

Kuda Betina : baiklah akan ku tunggu di tepi danau

Kuda Jantan : hati hati saat menyebrang

(kuda betina pun menyebrangi danau toba hingga sampai di tepi danau yang di maksud kuda jantan, ia pun berdiri tegak menanti kuda jantan hingga larut malam. Keesokan harinya beberapa masyarakat memperhatikan kuda betina yang berdiri tegak di tepi danau.

Masyarakat 2 : lihatlah sedari malam aku melihat kuda itu berdiri tegak di tepi danau.

Masyarakat 1 : aku juga melihatnya malam tadi ia berdiri tegak di sana seperti menanti sesuatu

Masyarakat 2 : ah sudahlah nanti ia juga Lelah dan pulang ke tempat asalnya

Masyarakat 1 : iya benar, kalua begitu ayo kita pergi 
(Beberapa hari berlalu masyarakat melihat Kuda betina yang masih berdiri di tepi danau dan menemui kuda tersebut)

Masyarakat 1 : lihat sudah tiga hari berlalu ia masih berdiri tegak di tepi danau itu

Masyarakat 2 : mengapa tidak kita tanya saja padanya langsung

Masyarakat 1 : apa yang kau lakukan disni

Kuda betina : aku sedang menunggu

Masyarakat 2 : apa yang seadang kau tunggu?

Kuda Betina : kekasihku, ia berjanji menemuiku di tepi danau ini.

Masyarakat 2 : sudah tiga hari kau berdiri di sini, apa kau tidak merasa Lelah

Kuda Betina : tidak, aku tidak akan Lelah ataupun beranjak dari tempat ini sebelum kekasihku datang

Masyarakat 1 : mengapa kau begitu yakin ia akan datang?

Masyarakat 2: iya mengapa kau begitu yakin, sementara kau sudah menunggunya tiga hari ini ia tak kunjung datang.

Kuda Betina : ia telah berjanji padaku akan menemuiku disini, ia tidak pernah ingkar janji

Masyarakat 2 : baiklah kalau begitu, kami pergi dulu. Jika kau membutuhkan sesuatu cari saja kami.

Kuda Betina : baiklah terimakasih.

(kedua masyarakat itupun beranjak pergi meninggalkan kuda betina sendiri di tepi danau, dan beberapa kali tetap memerhatikan kuda betina itu dari kejauhan. Hingga pada akhirnya kuda betina tersebut membatu di tepi danau dan kuda jantan pun tak kunjung datang

\subsubsection{Hasil Tanggapan Siswa Terhadap Legenda Batu Hoda}


Berdasarkan kategoris pertanyaan yang telah peneliti berikan kepada siswa serta berdasarkan cerita legenda Batu Hoda yang telah peneliti ceritakan kepada siswa secara langsung maka dapat dilihat bahwa pemahaman siswa terhadap legenda batu hoda sebelum diperkenalkan dalam naskah drama, beberapa siswa yang sangat antusias terhadap cerita Batu Hoda salah satunya Duwina yang memberi tanggapan serata pertanyaan ketika peneliti selesai menceritakan kisah legenda Batu Hoda di dalam kelas. Pertanyaan tersebut ialah "Bagaimana kondisi lokasi terjadinya legenda saat ini?" untuk menjawab pertanyaan dari salah satu siswa tersebut peneliti menjelaskan kondisi lokasi saat ini yang sudah dijadikan tempat wisata yang di beri nama Batu Hoda Beach.

Setelah menceritakan Legenda Batu Hoda kepada siswa, Peneliti mencoba memperkenalkan cerita Legenda Batu Hoda yang telah diubah menjadi naskah drama, antusiasme siswa untuk mengambil andil dalam pemeranan tokoh yang ada dalam naskah drama Legenda Batu Hoda merupakan gambaran bahwa besarnya kaingin tahuan siswa dalam kisah yang sama namun telah di transpormasi penyampaiannya agar lebih menarik. Namun dari pada itu adanya sedikit kesulitan dalam pemeranan tokoh Kuda Jantan dan Kuda betina dalam naskah menjadi tantangan kepada peneliti untuk memberikan arahan kepada siswa agar mampu mendalami peran tersebut yakni dengan memberikan ilustrasi.

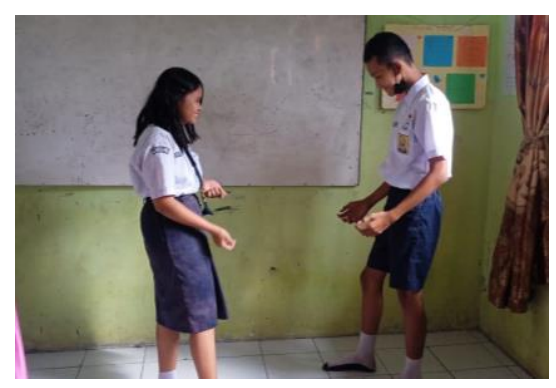

(1). Adegan kuda jantan dan kuda betina sebelum berpisah

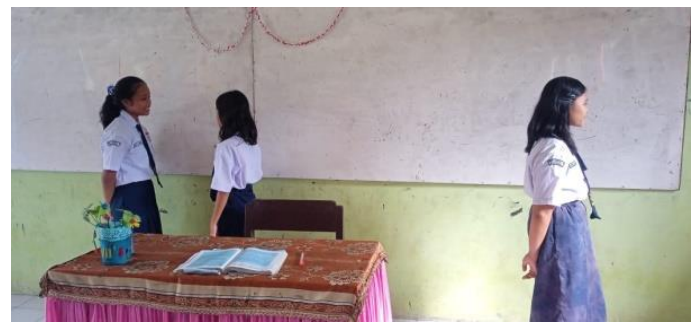

(2). Adegan saat kuda jantan menunggu kuda betina di tepi danau 


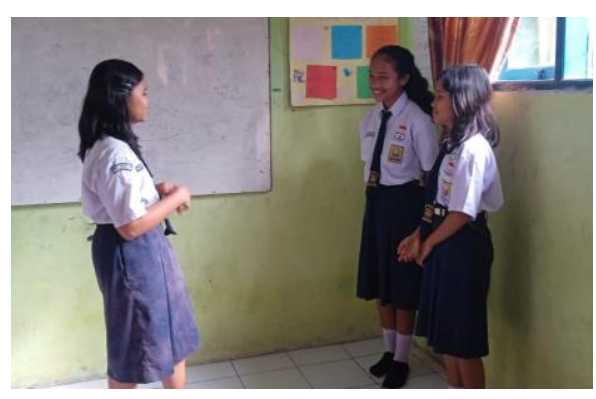

(3). Adegan saat masyaryakat memberi nasihat kepada kuda betina

\section{Data Responden:}

1. Syafira Ramadhani, 13 tahun, SMP Negeri 3 Sunggal.

2. Noviyana, 13 tahun, SMP Negeri 3 Sunggal.

3. Obet, 12 tahun, SMP Negeri 3 Sunggal.

4. Duwina, 13 tahun, SMP Negeri 3 Sunggal.

5. Deswita safitri, 12 tahun, SMP Negeri 3 Sunggal..

6. Alfredo Ginting, 13 tahun, SMP Negeri 3 Sunggal..

7. Reyhan Pinem, 12 tahun, SMP Negeri 3 Sunggal.

8. Rony Aldiansyah, 13 tahun, SMP Negeri 3 Sunggal.

9. Nazwa Khairunnisa, 13 tahun, SMP Negeri 3 Sunggal.

10. Daniel Sitinjak, 13 tahun, SMP Negeri 3 Sunggal. 


\section{Analisis:}

\begin{tabular}{|c|c|c|c|c|c|c|}
\hline \multirow[t]{2}{*}{ NO. } & \multirow{2}{*}{ NAMA } & \multirow{2}{*}{ PERTANYAAN } & \multicolumn{2}{|c|}{$\begin{array}{c}\text { TANGGAPAN } \\
\text { A }\end{array}$} & \multicolumn{2}{|c|}{$\begin{array}{c}\text { TANGGAPAN } \\
\text { B }\end{array}$} \\
\hline & & & $\mathbf{T}$ & TT & $\mathbf{S}$ & TS \\
\hline \multirow[b]{2}{*}{1.} & \multirow[b]{2}{*}{ Syafira } & $\begin{array}{l}\text { A. Apakah Kamu Mengetahui Legenda Batu } \\
\text { Hoda? }\end{array}$ & & & & \\
\hline & & $\begin{array}{l}\text { B. APakah kamu setuju jika Legenda Batu } \\
\text { Hoda di jadikan naskah drama dalam } \\
\text { pembelajaran ekstrakulikuler? }\end{array}$ & & & & \\
\hline \multirow[b]{2}{*}{2.} & \multirow[b]{2}{*}{ Noviana } & $\begin{array}{l}\text { A. Apakah Kamu Mengetahui Legenda Batu } \\
\text { Hoda? }\end{array}$ & & & & \\
\hline & & $\begin{array}{l}\text { B. APakah kamu setuju jika Legenda Batu } \\
\text { Hoda di jadikan naskah drama dalam } \\
\text { pembelajaran ekstrakulikuler? }\end{array}$ & & & & \\
\hline \multirow[b]{2}{*}{3.} & \multirow[b]{2}{*}{ Obet } & $\begin{array}{l}\text { A. Apakah Kamu Mengetahui Legenda Batu } \\
\text { Hoda? }\end{array}$ & & \multirow[t]{2}{*}{$\sqrt{ }$} & & \\
\hline & & $\begin{array}{l}\text { B. APakah kamu setuju jika Legenda Batu } \\
\text { Hoda di jadikan naskah drama dalam } \\
\text { pembelajaran ekstrakulikuler? }\end{array}$ & & & & \\
\hline \multirow[b]{2}{*}{4.} & \multirow[b]{2}{*}{ Duwina } & $\begin{array}{ll}\text { A. Apakah Kamu Mengetahui Legenda Batu } \\
\text { Hoda? }\end{array}$ & & \multirow[t]{2}{*}{$\sqrt{ }$} & & \\
\hline & & $\begin{array}{l}\text { B. APakah kamu setuju jika Legenda Batu } \\
\text { Hoda di jadikan naskah drama dalam } \\
\text { pembelajaran ekstrakulikuler? }\end{array}$ & & & & \\
\hline \multirow{3}{*}{5.} & \multirow{3}{*}{ Deswita } & $\begin{array}{ll}\text { A. Apakah Kamu Mengetahui Legenda Batu } \\
\text { Hoda? }\end{array}$ & & \multirow[t]{2}{*}{$\sqrt{ }$} & & \\
\hline & & $\begin{array}{l}\text { B. APakah kamu setuju jika Legenda Batu } \\
\text { Hoda di jadikan naskah drama dalam } \\
\text { pembelajaran ekstrakulikuler? }\end{array}$ & & & & \\
\hline & & $\begin{array}{l}\text { A. Apakah Kamu Mengetahui Legenda Batu } \\
\text { Hoda? }\end{array}$ & & $\sqrt{ }$ & & \\
\hline
\end{tabular}




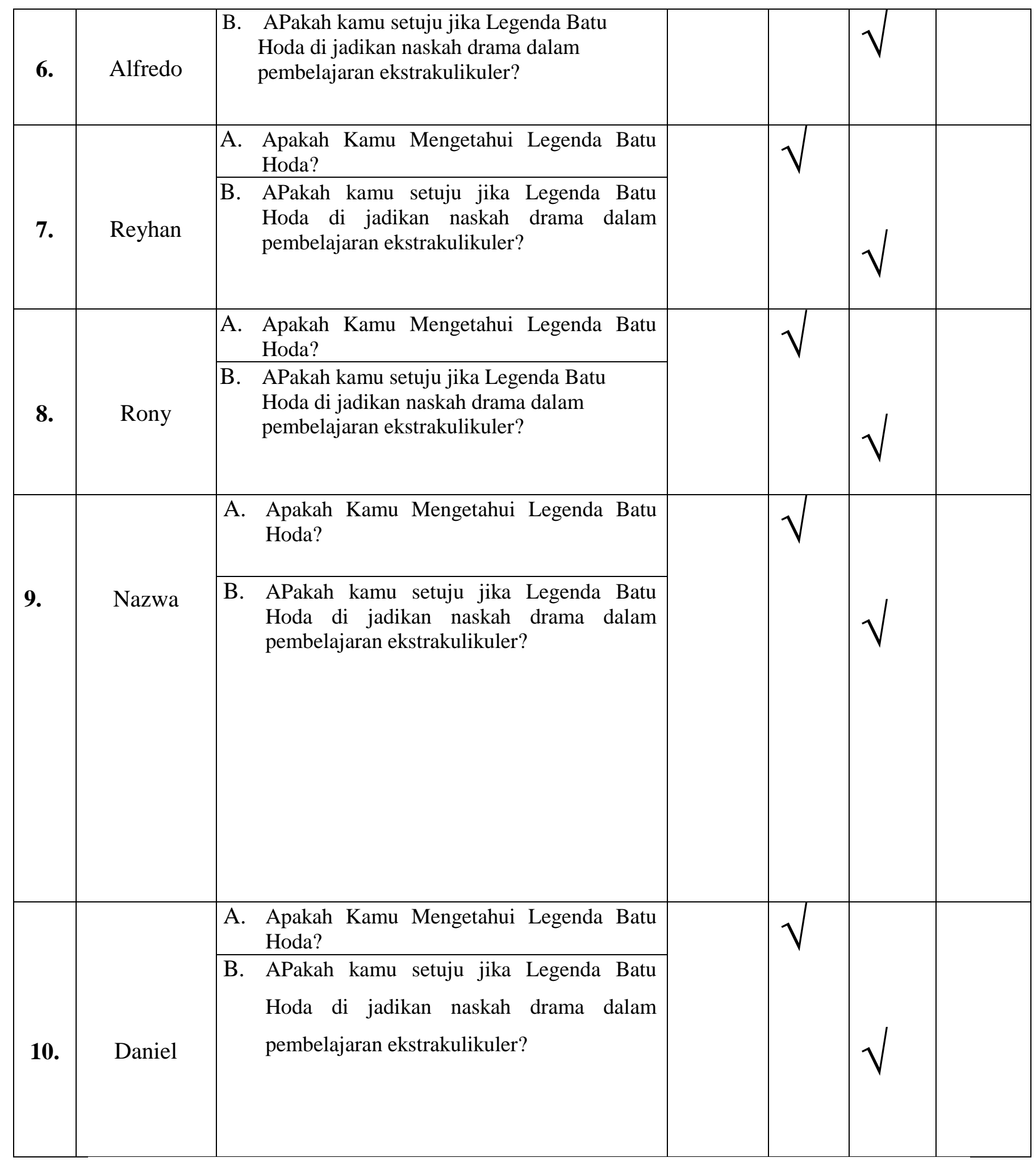




\section{Keterangan:}
S : Setuju
TS : Tidak Setuju
T : Tahu
TT : Tidak Tahu

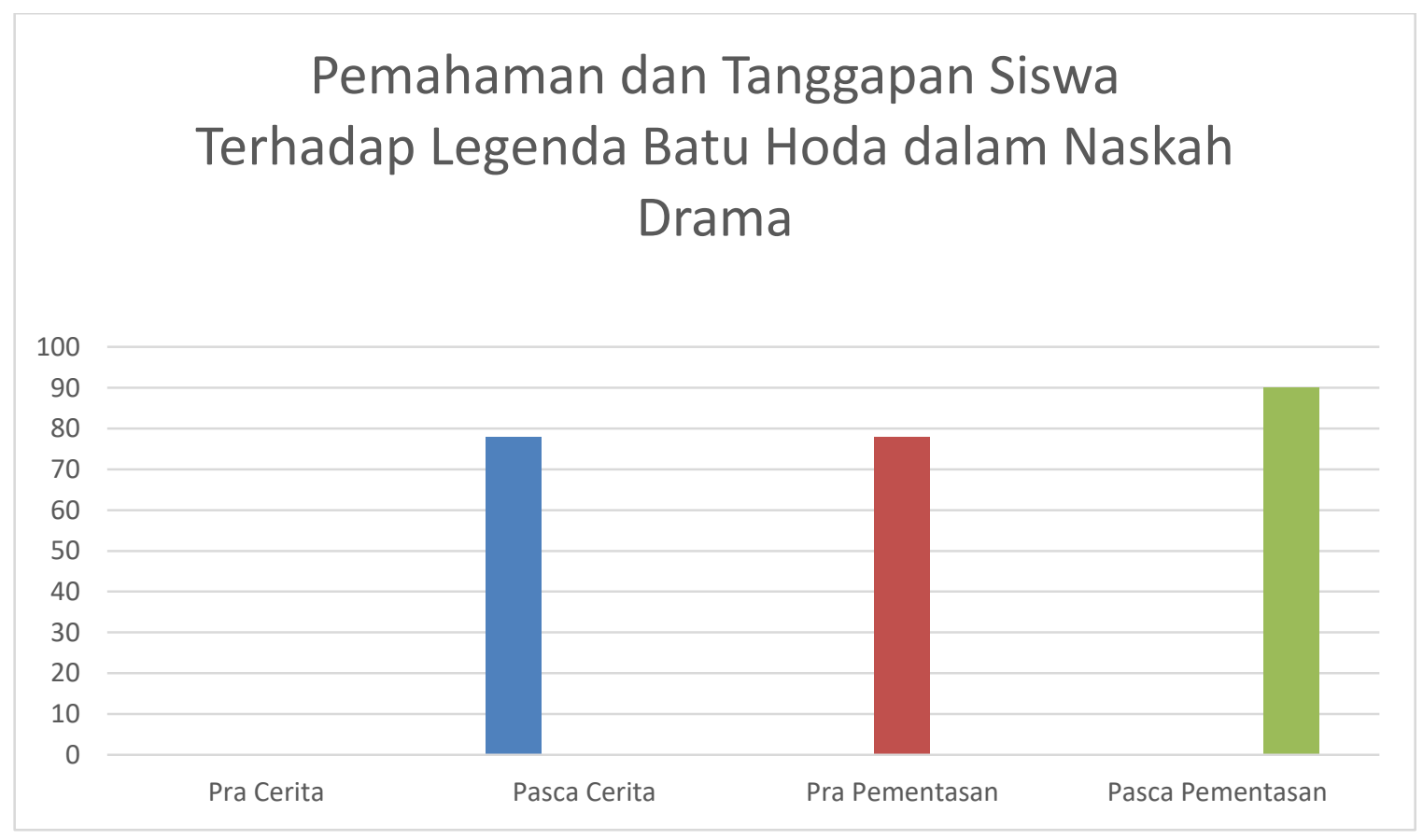

\begin{tabular}{|l|l|}
\hline Pra Cerita & $0 \%$ \\
\hline Pasca Cerita & $78 \%$ \\
\hline Pra Pementasan & $78 \%$ \\
\hline Pasca Pementasan & $90 \%$ \\
\hline
\end{tabular}




\section{Kesimpulan:}

Berdasarkan hasil penelitian kepada siswa, dapat di simpulkan bahwa Pemahaman siswa mengenai Legenda Batu Hoda sangatlah minim bahkan seluruh siswa masih belum mengenal Legenda Batu Hoda. Namun dibalik itu kaingin tahuan siswa sangatlah besar sehingga para siswa sangat merespon adanya penerapan drama dalam ekstrakulikuler sekolah dengan naskah Legenda Batu Hoda. Dengan ini adanya Naskah Drama Legenda Batu Hoda dapat mengenalkan legenda batu hoda kepada masyarakat khususnya kepada siswa serta dapat dijadikan bahan belajar dalam sekolah baik ekstrakulikuler maupun intrakulikuler. 


\section{PENUTUP}

\section{Kesimpulan}

Sesuai hasil penelitian yang dipaparkan pada bab sebelumnya dapat disimpulkan bahwa legengda dapat direvitalisasikan menjadi naskah drama.

Legenda "Batu Hoda" ini terbentuk karena pada zaman dahulu di sebuah Desa yang tentram hadir seekor kuda betina yang berdiri tegak di tepi danau menanti kekasihnya yang berjanji akan menemuinya ditepi danau toba tersebut, kemudian setelah beberapa lama kuda betina itu menunggu kuda jantan tidak kunjung datang menemuinya di tepi danau, hingga warga setempat yang melihat kuda betina itu merasa kasihan dan memberi nasihat kepada kuda betina itu untuk Kembali ke asalnya, namun kuda betina itu tidak akan Kembali tanpa kuda jantan. Dari legenda Batu Hoda ini dapat diambil kesimpulan bahwa penantian Wanita dan kesetiaan Wanita kepada pasangannya yang tidak di ragukan.

\section{Saran}

Legenda "Batu Hoda" yang telah disusun peneliti berdasarkan akurasi dari para informan dan penduduk sekitar Desa cinta dame, selanjutnya direvitalisasikan menjadi naskah drama, semoga bermanfaat bagi peneliti, pembaca, dan semua masyarakat yang yang telah membaca, ataupun menonton pementasan drama yang nantinya dibawakan oleh masyarakat umum ataupun siswa. Peneliti berharap semoga dengan adanya penelitian ini, semakin banyak peneliti yang mengangkat legenda daerah kita masing-masing dengan menggunakan media yang lebih mampu menarik minat anak tentang legendasetempat. 


\section{DAFTAR PUSTAKA}

Danandjaja, James. (2002). Folklor Indonesia: Ilmu gosip, dongeng, dan lain-lain. Jakarta: Grafiti.

Handayani Nst, S., Parapat, D. K., Marbun, P. F., Siregar, Y. E., \& Syahfitri, D. (2019). REVITALISASI LEGENDA DANAU LAU KAWAR MELALUI KOMIK. Jurnal Basataka (JBT), 2(2), 23-32.

Indriani, Yulianda. 2018. "Respons Anak Terhadap Cerita Rakyat Malin Kundang (Kajian Resepsi Sastra)". Jurnal Ilmiah Bahasa dan Sastra. 5(2) : 95-102.

Miles, M.B. and Humbermen, M.A. 1984. Qualitative Data Analysis, London: Sage Publication. Jurnal

Pranowo Sapto. 2020. Cerita Rakyat Terjadinya Kali Gowang Di Desa Budaya Giring Versi Suwondo

Rissari Yayuk, "Legenda anak durhaka: analsis Struktural tiga cerita lisan masyarakat banjar, kalimantan barat”. Balai Bahasa Provinsi Kalimantan Selatan.

Samuel Putra Anugrah Dan Baroto Tavip Indrojarwo, "Perencangan Komik Digital Legenda Singo Ulung Sebagai Media Pelestarian Rakyat Kabupaten Bondowoso". Skripsi program study Departemen Desain Produk Industri, Fakultas Arsitektur Desain Dan Perencanaan Institut Teknologi Sepuluh Nopember (ITS).

Sugiyono, 2009, Metode Penelitian Kuantitatif, Kualitatif dan R\&D, Bandung : Alfabeta

Sri Yono, "Revitalisasi Mitos Gunung Siklop (Cycloop): Sebuah Alternatif Konservasi Danau Sentani Melalui Sastra Lisan”. Balai Bahasa Provinsi Papua dan Papua Barat, Jalan Yoka, Waena, Distrik Heram, Jayapura. 
English Language Teaching Prima Journal, Vol. 3, No. 1. 2021

e-ISSN: 2686-1526

Pranowo Sapto. 2020. Cerita Rakyat Terjadinya Kali Gowang Di Desa Budaya Giring Versi Suwondo. 